\title{
Cholera Epidemic Prevention in Ningbo in 1930s and 1940s
}

\author{
Zhao Peiqing ${ }^{1}$ \\ ${ }^{1}$ Ningbo Science Middle High School, Ningbo, Zhejiang 315000, China \\ *Corresponding author. Email: zhaopeiqingtougao@163.com
}

\begin{abstract}
The Republic of China was a period of high incidence of cholera epidemic in Chinese history. Ningbo, a city located in the southeast coast of China, was also affected by cholera all the year round in the 1930s and 1940s. This paper purposes to use the local historical data of Ningbo to explore the epidemic situation of cholera in Ningbo in the 1930s and 1940s. It also tries to probe into epidemic prevention measures from all walks of life after the outbreaks, and provide some reference for the current epidemic situation and contribute to the study of the local history of Ningbo.
\end{abstract}

Keywords: Ningbo, Yin country, Cholera epidemic prevention, 1930s and 1940s

\section{PREFACE}

The Republic of China was one of the periods with high incidence of cholera in Chinese history. After the outbreak, local governments took a series of epidemic prevention measures. Previous epidemic prevention measures had become an important reference for epidemic prevention at present. In 1932, an extremely serious cholera epidemic broke out all over the country, and Ningbo was also greatly affected. The Ningbo area discussed in this paper is Yin area in the Republic of China. Its jurisdiction includes the present urban area, Cixi, Zhenhai, Ninghai, Xiangshan, Zhoushan and other areas, which was of typical significance in the social changes in modern China.

The purpose of this study is to use various local historical materials in Ningbo to explore cholera epidemic prevention in Ningbo, Zhejiang Province in the 1930s and 1940s. For example, the Current Affairs Bulletin [10] published in 1920, the Yin Tongzhi [6] published in 1951, the archives of the Republic of China kept in Ningbo Archives, the relevant archives of Ningbo Second Hospital (Huamei Hospital), Corning Hospital (Tongyi Hospital) "Annals of the 20th Anniversary of Tongyi Hospital" and "Ningbo Health Records", etc.

At present, the academic research on cholera epidemic prevention is mostly a special topic of urban public health. During the Republic of China, many scholars had discussed the evolution and development of China's public health at that time. For example, in the fourth chapter of History of Chinese Medicine [1], written by Chen Bangxian, discussed the development of modern medicine. After the founding of the People's Republic of China, especially since the 1980s and 1990s, the research on health history had gradually arisen, among which the most representative is $\mathrm{Yu}$ Xinzhong, a mainland scholar. In his book Health and Epidemic Prevention Mechanism in Qing Dynasty and Its Modern Evolution [5], he discussed the process of the concept of "health" from scratch in modern times and the influence of health and epidemic prevention in detail. Another book, Plague and Society in Jiangnan in Qing Dynasty-A Study of Medical Social History [4], took the outbreak of plague in Jiangnan in Qing Dynasty as the breakthrough point, This paper discussed the development and changes of Chinese society in the late Qing Dynasty. The author thought that the occurrence of an epidemic situation was not only a simple physiological phenomenon, but also had a great connection with the development of the whole society and social culture at that time. This view is also highlighted in another book of him Social Rescue under the Plague [3]. As a sudden social disaster, how did the society trigger the "social disaster stimulation mechanism" through or after the event, so that various measures for epidemic prevention were gradually constructed from all walks of life. As China's earliest trading port after the Opium War, Ningbo's development mode was quite different from that of inland cities. Luo Fuyun's book The Implications of Hygiene and Disease in China's Trade Ports [2] discussed the particularity of health and disease development in trading port cities compared with other 
cities, but Ningbo was only one part of it, there was no systematic study of Ningbo in the book.

At present, the academic circles have also published relevant papers on epidemic research, Professor Gong Shengsheng of Central China Normal University presided over the topic "Epidemic Disaster and Changes of Public Health Awareness during the Republic of China" which explored the epidemic situation of epidemic diseases in different regions during the Republic of China.This research started with the analysis of the epidemic situation and discussed the corresponding epidemic prevention measures in various regions, which provided a good idea for this research. However, these studies did not specifically deal with the epidemic situation of cholera. A Preliminary Study on the Response and Model of Cholera Epidemic in Shaanxi [9] and Fujian [8] during the Republic of China, in view of the epidemic situation of cholera in two places, the local countermeasures also had been deeply explored. However, the study area was far away from Ningbo, there were great differences in geographical location and climatic conditions, so there were great differences in cholera epidemic situation and epidemic prevention measures. The research of this paper aims to explore the epidemic prevention measures of all sectors of society in Ningbo during the Republic of China under the background of cholera epidemic, in order to provide some reference for the epidemic prevention measures under the current epidemic background.

\section{EPIDEMIC SITUATION OF CHOLERA IN NINGBO}

Cholera was an ancient and virulent infectious disease. After it was spread into China, it soon became one of the infectious diseases with extremely high mortality. In 1820, cholera was spread into Ningbo via waterway [7], and then there was a great epidemic in that year. Patients were killed immediately when his hamstring shrank. Therefore, Ningbo also called it Diaojiaosha. The southern region had a monsoon climate and was sultry and humid in summer, it was very easy to breed infectious diseases. Therefore, every summer and autumn, various infectious diseases often broke out in southern provinces and cities. Cholera was prevalent in Suzhou in 1932, 1942 and 1946-1947. "In late July (1942), many cholera cases were found in Suzhou City, and they were treated in isolation hospitals, all of which were found to be true cholera. According to the statistics of Suzhou Epidemic Prevention Committee, as of September 5th, there were 670 true cholera patients and 236 carriers, with a mortality rate of $44 \%$. "In the report, the cholera epidemic in Jiangsu was described as "rampant", and the death of patients occurred every day, with a high death rate of nearly half. Ningbo newspapers also reported the epidemic situation in other parts of the south of the Yangtze River. On August 16, 1942,
Ningbo's Current Affairs Bulletin published a report titled "True Tiger Liela Occurred in Wuxi, Jiaxing Prevents Tiger Epidemic Spread". The prevalence of infectious diseases in the south of the Yangtze River was widespread.

Due to the acute onset, rapid onset and ferocious onset of cholera, Ningbo dialect often called cholera "tiger epidemic (huyi) " or "tiger liela (huliela)".The cholera outbreak in 1932 was an infectious disease disaster with the greatest harm and the widest influence during the Republic of China. Except for a few provinces such as Xinjiang, the epidemic had almost spread all over the country. There were 100,666 cases in 306 cities across the country, with 31,974 deaths and a mortality rate as high as $31 \%$, which was extremely serious. Ningbo was also greatly affected by the cholera epidemic in 1932. In Yinxian Tongzhi, the number of cholera patients was 186 in 1931, 9533 in 1932, 87 in 1933 and 37 in 1934. From this set of data, it was not difficult to find that the cholera epidemic in 1932 was so powerful that the number of patients was significantly higher than that in other years. In other years, although the number of patients was small, there was no case of no patients. It is not difficult to see that cholera, an infectious disease, occurred year after year during this period.

In August 1932, the Current Affairs Bulletin published a large number of direct reports on the outbreak of cholera. "In Cixi City, the tiger epidemic is prevalent. Once infected with the epidemic, it can be killed in a few hours..... The infection is quite rapid, and the death pillow is notorious. The people of Cimin are very pale at the mention of the tiger. In the area of Hengjie, more than ten people have died from the epidemic." In mid-August, the epidemic still did not decline, and the number of cases per day was still high, so hospitals were not enough to treat it. The temporary hospitals under the epidemic situation were also very tense. More than 100 people have died.

Cholera often occurred in summer and autumn every year. In July 1942, cholera and death cases occurred in Ningbo City. By August 24, 1942, the number of people suffering from true cholera in the city had reached more than 10. According to the records of Yin County Government, the number of cholera patients in Ningbo in 1946 was 558.

According to the records of local materials, the cholera epidemic in the 1930s and 1940s of the Republic of China mainly showed several characteristics: first, the epidemic occurred every year, there was no time or year to eliminate cholera; Secondly, cholera was dangerous and fierce, and treatment delay was likely to endanger life. Finally, the cholera epidemic in 1932 was the most serious in the whole 1930s and 1940s. 


\section{CHOLERA EPIDEMC PREVENTION MEASURES IN NINGBO}

In 1928, the National Government published the Outline of the National Health Administrative System, which initially established the health administrative system, stipulating that all provinces needed to set up health departments and all counties and cities needed to set up health bureaus. In July, 1929, the health administrative institutions in Zhejiang Province gradually began to be constructed, and the fifth section under the provincial civil affairs department included epidemic prevention and health care. In September 1940, the Fifth Division set up the Zhejiang Provincial Health Department separately. Ningbo established municipal administrative divisions from 1927 to 1931, and then merged into Yin County. The epidemic prevention work of Yin County Government was directly affiliated to Zhejiang Provincial Health Department, which was an important part of the work of Yin Health Task Force. During the period of high incidence of cholera, what measures had been taken to prevent and control cholera in Yin County, and had they achieved the effect of epidemic prevention?

\subsection{Expanding the publicity of cholera disease}

As an exotic infectious disease, many people did not know about cholera, and knew nothing about prevention. Therefore, scientific propaganda of diseases was essential. In June 1932, the Yong Hong Society held a meeting to discuss how to publicize health methods in summer. It was decided that the Medical Committee would carry out team publicity and gave scattered health speeches to popularize cholera disease to the masses through street speeches.

In the Current Affairs Bulletin of August 1932, for several days, the "Cholera and its Prevention Measures" drawn up by Yin Temporary Epidemic Prevention Committee was published. First of all, it pointed out that cholera, as an international infectious disease, was very common in the world, but western countries had been able to control cholera in recent years, which showed that cholera was a preventable disease as long as our country also took appropriate measures." Considering that people knew little about cholera epidemic situation, the article introduced the pathogen, infection, water, flies, hands, incubation period, symptoms, diagnosis, treatment and prevention of cholera. This introduction was simple and progressive, which clearly explained the causes and possible modes of transmission of cholera. Even people who had no knowledge of cholera could form an understanding of cholera through reading newspapers. Increasing people's understanding of cholera could help people find cholera patients in time and send them to hospitals, which could not only save patients' lives, but also effectively reduced the spread of viruses in society.
As reading newspapers required a certain level of education and had a limited audience, the government had also actively publicized cholera diseases to the public through radio. On August 4, 1942, Ningbo Radio invited Zhang Junti, director of the Medical Department of the 10th Army, to broadcast the article "Terrible Tiger Epidemic". The original text was published in the Current Affairs Bulletin on the 6th. The radio also pointed out that the mortality rate of cholera in Ningbo is close to $50 \%$, far higher than that in Hong Kong and Shanghai. Therefore, "for the sake of health and safety in Ningbo, it was an urgent task to put out the tiger epidemic to prevent the tiger epidemic and realize military-civilian cooperation, publicize the horror of various infectious diseases to the people in the garrison, and unite with civil affairs and health authorities at all levels to help all walks of life deal with epidemic prevention affairs. Ningbo was still under the shadow of the Anti-Japanese War in 1942. The normal working order of the original administrative organs was affected. Many departments were merged into military and political departments. Therefore, the introduction by the army chief still had certain influence among the public. In addition, the government also invited Mao Huimin, chief physician of Yin Health Committee, to broadcast "Etiology and Prevention of Cholera". He cited the symptoms of cholera cases and called on the public to pay attention to cholera epidemic situation, and be careful about the food hygiene in daily life from a professional medical point of view.

Expanding the publicity of cholera diseases had also been included in the first content of Zhejiang Province's annual cholera prevention and control measures for counties and cities: "To expand publicity, counties and cities should hold an expanded publicity week from May 16 to the end of June to promote the attention of the people." The Yin government also actively prepared for the summer health and epidemic prevention campaign in May and June every year. In the preparatory meeting, the date of the sports week, the sources of funds and matters needing attention were carefully deployed in advance to ensure the smooth progress of the Health and Epidemic Prevention Publicity Week.

Efforts to make more people know the source and development process of cholera epidemic could help people distinguish cholera diseases in time, send patients to hospitals in time, and stay away from the articles that patients have contacted with. On the one hand, it could save patients' lives in time, and on the other hand, it could reduce the possibility that patients continue to spread cholera bacteria. However, if people could not distinguish cholera from other diseases, but only thought that cholera was a common intestinal disease, it would increase the possibility that the patient's condition may become more and more serious, and it would also increase the possibility of cholera spreading. Therefore, it was very necessary to carry out scientific publicity on cholera 
disease, and it was also a basic step to effectively prevent cholera.

\subsection{Giving vaccination}

At the end of the 18th century, British doctor Edward first discovered that milkmaids suffering from vaccinia had certain resistance to smallpox, a very serious infectious disease at that time, and thus invented the method of "vaccination" to prevent smallpox, which was the original source of vaccine. At the end of the 19th century, Pasteur conducted in-depth research on vaccines and successfully developed vaccines for various infectious diseases. Since then, vaccines had become the most effective means to prevent infectious diseases. In 1883, after the cholera arc bacteria were successfully isolated, the vaccine was also born in the second year. Injection of cholera vaccine could greatly reduce the risk of cholera infection, and even if the disease was ill, it could also relieve the symptoms of the disease. In the prevention and control of cholera epidemic in Ningbo in the 1930s and 1940s, cholera vaccination was one of the priorities.

The government organized all sectors of society to actively participate in the work of vaccination, and widely published the message of vaccination in newspapers, advocating citizens to actively go for vaccination. At the beginning of June, the Ningbo Red Cross held several councils and decided to start vaccination on a regular basis in sub-districts. From June 15 to August 15, 1932, vaccination was given on the Drum Tower in the center of Ningbo City from $2 \mathrm{pm}$ to 4 pm every day. It was clearly pointed out that the cost of medicine and injection was free. In order to facilitate people in different regions to be vaccinated nearby, it was specially divided into seven places. The addresses set up by Ningbo Red Cross Society for vaccination basically covered most of the geographical areas of Ningbo City at that time, and nearby residents could be vaccinated nearby. In order to popularize vaccination, the principal of Wufeng School in Zhucun, Fenghua, together with the local villagers and the village head, agreed to hire doctors to give cholera vaccination to the villagers from house to house.

Kaiming Hospital had repeatedly published the "Notice on Implementing Epidemic Prevention" in newspapers. "Every Monday, 25, the injection is delivered from 9 am to $12 \mathrm{am}$." Hu Yiqin, president of Minsheng Hospital, joined hands with Mr. Chen Baolin and Mr. Yu Jimin, who were famous in Ningbo at that time, to publish notice on the newspaper, urging people to take vaccination, and all people who went to Minsheng Hospital to take vaccination were exempted from fees. This statement appeared in the same page of Current Affairs Bulletin almost throughout June 1932. In order to prevent people from escaping to receive vaccination due to economic reasons, the cost of vaccination would be exempted. A special fund had also been set up to assist the elderly with vaccination. At the Fifth Council of Ningbo Red Cross Society, it was decided that "President Yuan Duanfu will keep the 1,000 oceans donated by Shanghai businessmen to assist the elderly with vaccination". In order to popularize vaccination, Zhenhai Tongyi Hospital "sends doctors from the hospital to tour villages" and "a large number of people come to the hospital to receive vaccination". It could be seen that all sectors of society hoped to inject vaccination more widely and gave full play to the epidemic prevention effect that vaccination could bring.

Huamei Hospital, as the largest private hospital in Ningbo at that time, developed vaccination every summer. The work report of Huamei Hospital recorded the number of cholera vaccinations in the 1940s. Among them, the total number of injections was 32,458 in 1943 , 14,295 in 1944 and 5,204 in 1945. It was worth noting that Huamei Hospital not only provides cholera vaccines for the public, but also had vaccines specifically for schools. In 1946, Huamei Hospital received 6,768 vaccines for the public. In addition, there were vaccines specifically for schools, with a total of 4,612 vaccines. The advantage of school vaccination was that it could complete the vaccination of all students comprehensively, timely and quickly, and the school environment was relatively closed. If cholera transmission occurs, it was often difficult to control it. If cholera vaccination was unified in schools, it could effectively prevent and control the large-scale transmission of cholera in schools.

The following table shows the number of cholera vaccines in the summer of 1946 and 1947 recorded in Yin County's "Report Form on County Vaccination and Vaccination Number". Judging from the number, in the month of high incidence of cholera, more than 1,000 people went to receive vaccination every day. Such figures could still play a positive role in the prevention and control of cholera epidemic.

Table 1. Yin County Vaccination and Vaccination Number Report Form

\begin{tabular}{|l|l|l|l|}
\hline Time & $\begin{array}{l}\text { Number of } \\
\text { cholera } \\
\text { injections } \\
\text { (male) }\end{array}$ & $\begin{array}{l}\text { Number of } \\
\text { cholera } \\
\text { injections } \\
\text { (female) }\end{array}$ & Total \\
\hline June 1946 & 22351 & 16025 & 38376 \\
\hline July 1946 & 25034 & 14067 & 39101 \\
\hline $\begin{array}{l}\text { August } \\
1946\end{array}$ & 19051 & 11406 & 30907 \\
\hline $\begin{array}{l}\text { September } \\
1946\end{array}$ & 14373 & 8939 & 23372 \\
\hline $\begin{array}{l}\text { October } \\
1946\end{array}$ & 497 & 195 & 692 \\
\hline June 1948 & 331 & 311 & 642 \\
\hline July 1948 & 5227 & 2023 & 7250 \\
\hline $\begin{array}{l}\text { August } \\
1948\end{array}$ & 45073 & 12583 & 57656 \\
\hline
\end{tabular}

Source: Ningbo Archives: J12-1-14 
It was clearly pointed out that cholera vaccination must be actively promoted in The Measures for the Implementation of Cholera in the 35th Year of the Republic of China promulgated by Zhejiang Province . The number of people injected must reach more than $50 \%$ of the county's total population. After injection, an injection certificate would be issued, and all local government, school and group personnel would be forced to inject." In the inaugural meeting of the epidemic hospital in the same year, it was decided to check the results of injection of vaccines. "From July 17, the Ningbo Police Department and the quarantine team of the Epidemic Prevention Committee would carry out spot checks, and the general inspection would be held from July 26. If there were still people who had not been injected with vaccines, they should be punished."

During the whole process of cholera prevention and control in Ningbo in the 1930s and 1940s, the government continuously advocated citizens to actively inject vaccines through newspapers, radio and other publicity methods. Major hospitals in Ningbo also actively cooperated with the injection work. Vaccine injection was not only the top priority in the overall epidemic prevention plan, but also had certain mandatory injection itself. Compulsory injection was implemented for personnel of schools, government agencies and organizations, while other citizens urged them to complete the injection through inspection, which could play a positive role in the prevention and control of cholera epidemic.

\subsection{Setting up temporary epidemic hospitals}

In the outbreak season of cholera, the number of patients increased greatly in a short time, sometimes exceeding the load capacity of a hospital. At the same time, cholera, as an infectious disease, should be treated in hospitals with strong isolation and disinfection capabilities. If cholera was treated together with common diseases, the risk of cross-infection may increase. Therefore, the establishment of temporary epidemic hospitals was also an important measure to prevent and control cholera.

After the outbreak of the tiger epidemic in 1932, the Yin Doctors' Union immediately convened a meeting of doctors from all counties to discuss the establishment of the epidemic hospital, elected Zhou Dalie as its president, and decided to establish the "Yin Union Temporary Epidemic Hospital". All preparations for the temporary hospital were discussed in the meeting, and the temporary hospital was opened immediately. The military and police circles were also very concerned about the establishment of temporary hospitals, demanding that hospitals should be set in each district. The original military hospital was also temporarily ended and changed into a epidemic hospital. In Meixu, a town of Yin County, due to the unusually hot weather and rampant tiger epidemic since the beginning of summer. Lu Shikui, director of the Sixth Public Security Bureau of the area, thought that there was no place to cure the epidemic, which led to the villagers not being treated in time and aggravated the spread of the epidemic. "The local gentry Ling Baoting and others were called together to launch the establishment of Meijiang Epidemic Hospital for first aid." And officially opened the clinic on August 1st. At the same time, on August 1st, the Epidemic Hospital jointly organized by Ningbo Red Cross Society and Physicians' Union was opened in Taisui Hall, North Gate. Yin County Temporary Epidemic Hospital not only hired doctors from the former County Central Hospital, but also hired a doctor and six nurses from Hangzhou to support it. With all the wards, medicines and personnel available, it officially began to accept cholera patients on August 10 th, and all medical expenses were free.

However, the epidemic was so serious that some hospitals still suffer from inadequate medical treatment. The epidemic department of Jiangbei Renji Hospital only had two doctors and four nurses in the epidemic department of the hospital. As the epidemic became more and more serious, they could not cope with it at all. People from all walks of life in Jiangbei were deeply worried about this. "Yesterday, a joint letter was sent to the founder of the hospital, Du Yuesheng Jin Tingsun, asking him to hire more doctors, or temporarily stop the diagnosis of common diseases, so as to fully diagnose and treat the epidemic for treatment." Ren Xingeng, president of Yin Second Hospital, specially set up the temporary epidemic department in view of the serious epidemic disease, and hired the necessary doctors and nurses, in order to cope with the continuous development of the epidemic disease calmly.

In the Current Affairs Bulletin on the 17th of that month, it was announced that the hospitals for cholera in Yin County were "Yin County Temporary Epidemic Hospital, the Epidemic Hospital jointly organized by Ningbo Red Cross Society and Yin Doctor Union, Renji Hospital Epidemic Department, Jiangdong Epidemic Hospital, Shiqi Temporary Epidemic Prevention Institute, Yinnan Sanxiang Temporary Epidemic Prevention Institute Fenghuang City Epidemic Hospital." It was worth noting that the hospitals listed in the newspaper specifically indicate that the above hospitals would not accept any medical and drugs funds . On the one hand, this measure could prevent citizens from not going to see a doctor due to economic reasons, and reduced the number of patients in society to a certain extent; On the other hand, it was also the embodiment of the active support of the government and all sectors of society for epidemic prevention.

Setting up standardized temporary epidemic hospitals could also help the government to collect the preparation status of each hospital and the statistics of the number of sick deaths better. In autumn, the ferocious cholera 
epidemic gradually decreased, and the major epidemic hospitals came to an end. Ningbo Municipal Public Security Bureau specially ordered hospitals in various epidemic departments to fill in statistical forms to make statistics on the epidemic situation in 1932. Accurate and scientific records of cholera development could not only objectively reflect the historical situation of that year, but also provided reference value for future epidemic prevention work.

According to the records in Yin Tongzhi, in 1933, there were five county hospitals in Yin county, the Central Hospital, the First, Second, Third and Fourth Hospitals, all of which treated internal and external surgery. In addition, there were 18 private hospitals in Yin County in 1931. Among them, Huamei Hospital and Jiangbei Renji Hospital, had relatively great influence. Although there were many hospitals in Yin County as a whole, and people from all walks of life had also actively set up epidemic hospitals after the outbreak of the epidemic. However, no special hospital for infectious diseases had been set up in Yin District. Zhejiang Province had issued the 35-year Implementation Measures for Cholera Prevention and Control in Ningbo Central Hospital, designating Huamei Hospital, Ningbo Central Hospital and Zhenhai Tongyi Hospital as the responsible institutions for cholera inspection and treatment. However, these three hospitals were all general hospitals, not hospitals specializing in treating infectious diseases. In the long run, this was not conducive to the overall co-ordination of epidemic diseases.

With the occurrence of epidemic diseases year after year, people from all walks of life were also aware of this deficiency in Yin area. On July 9, 1946, Wang Shizhang, the director of Ningbo Epidemic Prevention Committee, petitioned for the establishment of Ningbo Epidemic Hospital. The county government responded quickly. On 15th, Ningbo Epidemic Hospital was established and held its first inaugural meeting, in which the preparation process of the epidemic hospital and the recent epidemic situation were reported. Since then, Yin District had set up a medical institution specializing in the treatment of infectious diseases, which was not only convenient for citizens to go to see a doctor after the outbreak of the disease, but also could help Yin District to make overall plans for various measures for epidemic prevention and control.

In 1936, it was decided by the 6th meeting of Yin Government that the epidemic hospital was reorganized into Ningbo Infectious Disease Hospital after its work was completed. On February 5, 1937. Ningbo Infectious Disease Hospital was formally established. The government allocated 10 million yuan per month for the hospital, and the county health committee allocated 3,500 catties of rice per month for the fund. It was clearly pointed out that the purpose of the establishment of the
Infectious Disease Hospital was to assist various infectious disease medical institutions and prevent the large-scale epidemic of infectious diseases in Ningbo. Ningbo Infectious Disease Hospital was a public medical institution with a board of directors, a clinic, a laboratory and a pharmacy office. The hospital planned to set up a general ward and an isolation ward, as well as a tuberculosis sanatorium and a corresponding central clinic. There were full-time and part-time medical staff employed. It was clearly pointed out that medical personnel should be temporarily employed during cholera epidemic season, and the board of directors should launch social fund-raising. It could be seen that the prevention and control of cholera epidemic was a focus of Ningbo Infectious Disease Hospital and could also promote the overall prevention and control of cholera epidemic.

The purpose of setting up an epidemic hospital was to treat cholera patients in a more timely manner and to prevent patients from causing more infections in society. Cholera epidemic occurred all the year round in Yin County in 1930s and 1940s. All sectors of society took a positive attitude towards setting up temporary epidemic hospitals, and set up special infectious disease hospitals in 1940s, which played a positive role in the overall epidemic prevention and control in Yin County.

\subsection{Improving public health}

Due to the hot summer weather in summer, Ningbo residents often like to eat raw and cold fruits or vegetable to relieve the summer heat. If vegetables are washed with water contaminated with bacteria, the possibility of illness will be greatly increased. At the same time, in summer, small vendors selling cold drinks often appear on the streets of Ningbo. Some vendors have very poor sanitary conditions and often become hotbeds of germs. Cholera bacteria mainly take water as the carrier, and flies may also be a medium of transmission. If the environment is cleaned in a standardized way and good environmental sanitation is maintained, the spread of cholera bacteria can be greatly reduced. Therefore, maintaining good environmental sanitation and the construction of tap water are also a key point of epidemic prevention work.

In 1931, the Yin government put forward a work plan of "preventing epidemic diseases, holding summer cleanup campaigns, cleaning rivers and paying attention to the cleaning of drinking water materials" for health matters in the executive meeting. And designated a special cleaning method for summer cleaning, The Ningbo Public Security Bureau of the county party department and county government and the association jointly organized the cleaning inspection team to inspect, government organizations and schools were inspected by the county party department and county government and this Council, hotels, restaurants were inspected by Ningbo Public Security Bureau, Store residents should check carefully. The six district offices and health branches in 
the city sent personnel to publicize them in advance. According to the cleaning methods recorded in the county annals, the government had formulated a relatively complete work plan for the summer cleaning work, and different organizations and different organs had implemented the inspection of the cleaning effect to improve the overall sanitation situation of the city.

Because the concepts of bacteria and disinfection had not penetrated into the traditional public concept, these people were the main group to improve the overall public health. Therefore, the promotion of basic health concepts was the primary task to improve public health. In August, 1932, Current Affairs Bulletin published "Autumn Hygiene Points" formulated by Yin Epidemic Prevention Committee, which included nine hygiene points, wiping up flies, not eating flies, not drinking raw water, not eating cut and soaked melons and fruits, strictly disinfecting patients' urine and feces, wiping up mosquitoes, and not cooling at night. According to the old living habits of residents in Yin area, Yin Epidemic Prevention Committee formulated this health point according to local conditions, advocated residents to develop good health habits, and reduced the spread of bacteria through bad living habits.

\subsection{Nongovernmental and public epidemic prevention}

Ningbo was one of the five foreign trade ports after the Opium. After the opening of the port, a large number of western learning and modern scientific and technological thoughts were introduced into Ningbo, which greatly impacted the old way of life and thinking in this city. The whole city presented the typical characteristics of "combine traditional Chinese features and modern Western characteristics". This feature was also reflected in the prevention and treatment of cholera diseases. The epidemic prevention measures mentioned above are all based on western medicine and modern bacteria theories. In fact, after the outbreak of the epidemic, there were still a few citizens in Ningbo who prevented and treat the epidemic through traditional folk methods. At the same time, due to the rapid onset of cholera, panic was often caused among the masses, linking the disease with the gods of heaven and earth, believing that one's own behavior violates the gods, and then bad luck come. As a result, people got the epidemic should hold a ceremony to sacrifice to the gods in order to beg for their forgiveness. This kind of epidemic prevention measures by citizens was useless at all. Judging from the newspaper reports on such incidents, sacrificial activities were not the mainstream in the process of preventing and controlling epidemic diseases. Sacrificial activities in Yinnan area had also been dispersed by police. Such acts belonged to the traditional dross in the process of epidemic prevention. This situations further proved the importance of implementing cholera diseases and strengthening public health publicity in the process of epidemic prevention.

In the process of people's spontaneous epidemic prevention, there were also some charitable residents who hoped to contribute their strength to the society despite their limited ability. After the outbreak of cholera in 1932, Mao Shunqing, director of Ningbo Cotton and Wool exchange, initiated the establishment of a voluntary clinic, which officially opened on June 15 th. In order to let more citizens know this message, this advertisement appeared in the same edition of the newspaper for 3 consecutive days. In the same year, Wang Qingsheng, a staff member of the Water Conservancy Bureau, bought Shidishui, Changchun Dan and other medicines by his own expense every day, and gave medicines to the poor free of charge in crowded places such as stations and docks. A total of "750 bottles of Shidishui, 300 bottles of Changchun Dan, 500 bottles of Jisheng Dan, and 70 bottles of moral medicine."

The occurrence of epidemic disease was a social situation that all citizens do not want to see, and it was also a huge disaster for every family that encounters it. In the face of the epidemic, all people hoped to get through it smoothly and safely. Limited by traditional concepts and economic level, there were still some citizens who use traditional methods to face the epidemic in society. At the same time, there were also people who are interested in charity and help citizens resist the epidemic with medical means. Traditional epidemic methods coexisted with modern medical epidemic methods, which was also a typical feature of cholera epidemic prevention and control in Ningbo in 1930s and 1940s, it presented the feature of "combine traditional Chinese features and modern Western characteristics".

\section{CONCLUSION}

In the 1930s and 1940s, cholera was prevalent in Ningbo. The local government of Ningbo had also taken corresponding measures to prevent and control the epidemic. From the overall situation, the attitude of the government and all sectors of society towards the prevention and control of the epidemic were relatively positive. In terms of prevention and control measures, it not only publicized cholera itself, actively gave vaccination and builds temporary epidemic prevention hospitals, but also paid attention to public health in Ningbo from a macro perspective and advocates people to form scientific health concepts. At the same time, the government could actively mobilize forces from all walks of life to prevent and control the epidemic in various ways, which played a positive role in the overall development of society at that time. This article mainly combs and studies the epidemic and prevention of cholera in Ningbo in the 1930s and 1940s, hoping to provide reference for the current epidemic of infectious diseases, 
and also hope to promote the study of Ningbo's local history and make it gradually rich and perfect.

\section{REFERENCES}

[1] Chen Bangxian, Zhongguo Yixue Shi [Chinese Medical History]. Beijing: The Commercial Press, 1937.

[2] Luo Fuyun, Zhongguo Tongshang Kouan Weisheng Yu Jibing De Hanyi [The Implications of Hygiene and Disease in China' s Trade Ports]. Nanjing: Jiangsu People's Press, 2007.

[3] Yu Xinzhong, Wenyixia De Shehui Zhengjiu [Social Rescue under the Plague]. Beijing: China Bookstore, 2004.

[4] Yu Xinzhong, Qingdai Jiangnan De Wenyi Yu Shehui [Plague and Society in Jiangnan in Qing Dynasty-A Study of Medical Social History]. Beijing: Beijing Normal University Press, 2014.

[5] Yu Xinzhong, Qingdai Weisheng Fangyijizhi Jiqi Jindai Yanbian [Health and Epidemic Prevention Mechanism in Qing Dynasty and Its Modern Evolution]. Beijing: Beijing Normal University Press, 2016.

[6] Zhang Chuanbao and Wang Huanzhang, Yinxian Tongzhi [The General History of Yin County]. Ningbo: Yinxian Tongzhi Guan, 1951.

[7] Zhang Qingkun, Ningbo Weisheng Zhi [Ningbo City Health History]. Ningbo: Ningbo City Health Bureau, 1989.

[8] Chen Yi, Minguo Shiqi Fujian Huoluan Yanjiu [Research on Cholera in Fujian during the Republic of China] Ma thesis: Fujian Normal University, 2009.

[9] Yang Yuqian, 1932 nian Shanxi Huoluan Yanjiu [Research on Cholera in Shaanxi in 1932] Ma thesis: Shanghai Jiaotong University, 2003.

[10] A Guide to Citation, Shishi Gongbao [Current Affairs Bulletin](Daily Edition), 1920. 